\title{
Systemic gene delivery into soybean by simple rub-inoculation with plasmid DNA of a Soybean mosaic virus-based vector
}

\author{
Jang-Kyun Seo $\cdot$ Hyeok-Geun Lee $\cdot$ \\ Kook-Hyung Kim
}

Published online: 24 July 2009

(C) Springer-Verlag 2009

\section{Erratum to: Arch Virol (2009) 154:87-99 DOI 10.1007/s00705-008-0286-4}

In the published article, some statements should be changed as indicated below. It was a misstatement of fact to claim that Soybean mosaic virus is a novel gene expression vector for soybean in light of the earlier disclosure published in Mol Plant Microbe Interact 19:304-312 (2006) by Wang et al. Therefore, the following amendments should be made to the text.

1. On page 88 lines 26-34 (left panel), the statement "Recently, Bean pod mottle virus (BPMV) and Cucumber mosaic virus (CMV) have been engineered as gene delivery vectors and successfully adopted for stable expression of target proteins in soybean [39, 60]. However, since these viral vectors were constructed to generate recombinant viral RNAs by in vitro transcription, the costs associated with these procedures may be considerable if viral vectors are to be used to evaluate large numbers of genes." should be revised as follows "Recently, Bean pod mottle virus (BPMV), Cucumber mosaic virus (CMV) and SMV have been engineered as gene delivery vectors and successfully

The online version of the original article can be found under doi:10.1007/s00705-008-0286-4.

J.-K. Seo · H.-G. Lee · K.-H. Kim $(\bowtie)$

Department of Agricultural Biotechnology,

College of Agriculture and Life Sciences,

Seoul National University, Seoul 151-921, South Korea

e-mail: kookkim@snu.ac.kr

J.-K. Seo $\cdot$ K.-H. Kim

Institute of Molecular Biology and Genetics,

Seoul National University, Seoul, South Korea adopted for stable expression of target proteins in soybean [39, 55a, 61]. However, since these viral vectors were constructed to generate recombinant viral RNAs by in vitro transcription or biolostic delivery of cDNA, the costs associated with these procedures may be considerable if viral vectors are to be used to evaluate large numbers of genes."

2. On page 97 lines 7-10 (left panel), The sentence "Moreover, to our knowledge, this is the first report demonstrating the feasibility of using SMV as an efficient expression vector for stable expression in soybean." must be corrected as follows "We have also engineered this SMV construct as an efficient expression vector for stable expression in soybean. Although it was previously demonstrated that SMV can be used as a gene delivery vector [55a], in this study we further showed that foreign genes can be systemically delivered to soybean by simple rub-inoculation with plasmid DNA of SMV-based vector."

3. On page 98 line 60 (right panel), add an additional reference as $55 \mathrm{a}$.

[55a. Wang L, Eggenberger A, Hill J, Bogdanove AJ (2006) Pseudomonas syringae effector avrB confers soybean cultivar-specific avirulence on Soybean mosaic virus adapted for transgene expression but effector avrPto does not. Mol Plant Microbe Interact 19:304-312]. 